\title{
CANCER OF THE LARGE BOWEL
}


Previous volumes in the series

Volume 1 Cancer of the Oesophagus

Edited by H. R. Matthews et al. 1987. 184 pp.

Volume 2 Cancer of the Larynx

Edited by P. E. Robin et al. 1988. 238 pp.

Volume 3 Cancer of the Stomach

Edited by J. W. L. Fielding et al. 1989. 246 pp. 


\title{
Cancer of the Large Bowel
}

\author{
Edited by
}

Sir Geoffrey Slaney, KBE, MSc, ChM, FRCS

Emeritus Professor of Surgery

University of Birmingham, and

Honorary Consultant Surgeon

Queen Elizabeth Hospital

Birmingham, England

$$
\text { and }
$$

Jean Powell, BSc, FIS Christopher C. McConkey, BSc

John A. H. Waterhouse, MA, PhD, HonFFOM

Ciaran B. J. Woodman, MB, BCh, BAO, MRCOG, MFCM, MD

Regional Cancer Registry

Queen Elizabeth Medical Centre, and

Cancer Epidemiology Research Unit

University of Birmingham

Birmingham, England

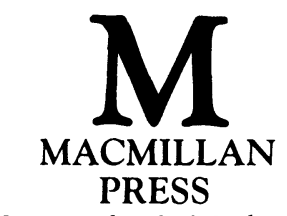

Scientific \& Medical 
(C) The authors 1991

Softcover reprint of the hardcover 1st edition 1991

All rights reserved. No reproduction, copy or transmission of this publication may be made without written permission.

No paragraph of this publication may be reproduced, copied or transmitted save with written permission or in accordance with the provisions of the Copyright, Designs and Patents Act 1988, or under the terms of any licence permitting limited copying issued by the Copyright Licensing Agency, 33-4 Alfred Place, London WC1E 7DP.

Any person who does any unauthorized act in relation to this publication may be liable to criminal prosecution and civil claims for damages.

First published 1991

Published by

MACMILLAN ACADEMIC AND PROFESSIONAL LTD

Houndmills, Basingstoke, Hampshire RG21 2XS

and London

Companies and representatives

throughout the world

British Library Cataloguing in Publication Data

Cancer of the large bowel.

1. Man. Large intestine. Cancer

I. Slaney, Geoffrey II. Series

616.994

ISBN 978-1-349-11422-1

ISBN 978-1-349-11420-7 (eBook)

DOI 10.1007/978-1-349-11420-7

ISSN 0954-7495 


\section{Contents}

Foreword, by Professor P. Gilroy Bevan

1 Introduction and Methods 1

$\begin{array}{llr}1.1 & \text { Introduction } & 1 \\ 1.2 & \text { Inclusion criteria } & 2 \\ 1.3 & \text { Data base } & 3 \\ 1.4 & \text { Validation procedures } & 3 \\ 1.5 & \text { Survival data } & 4 \\ 1.6 & \text { Statistical methods } & 5 \\ 1.7 & \text { Population } & 6 \\ \text { Figure } 1.7 & \text { 1961 and 1981 census population pyramid } & 8 \\ \text { Table } 1.7 .1 & \text { Comparison of social factors } \\ \text { Table } 1.7 .2 & \text { Population densities } \\ \text { Table } 1.7 .3 & \text { Populations used for the different time } \\ & \quad \text { periods } & 10 \\ 1.8 & \text { General arrangement } & 11\end{array}$

2 Epidemiology: Demographic aspects 12

$\begin{array}{ccll}\text { Table 2.1 } & \text { Summary } & 12 \\ \text { Table } 2.2 & \begin{array}{l}\text { Incidence rates by quinquennium and sex } \\ \text { (all subsites) }\end{array} & 14 \\ \text { Table 2.3 } & \begin{array}{c}\text { Number per annum by sex (excluding certain } \\ \text { sites) }\end{array} & 15 \\ \text { Figure 2.3 } & \begin{array}{l}\text { Number per annum by sex (excluding certain } \\ \text { sites) }\end{array} & 16\end{array}$


Table 2.4 Figure 2.4 Table 2.5 Table 2.6.1 Table 2.6.2 Table 2.7.1 Table 2.7.2 Table 2.7.3 Figure 2.7.3 Figure 2.8.1 Figure 2.8.2

Figure 2.8.3

Figure 2.8.4

Table 2.9

Figure 2.9

Table 2.10

Table 2.11

Table 2.12.1

Table 2.12.2

Figure 2.12

Table 2.12.3

Table 2.13.1

Table 2.13.2

Table 2.14.1

Table 2.15.1

Table 2.15.2

Figure 2.16.1

Table 2.16.

Figure 2.16.2

Table 2.17

Figure 2.17
Table 2.14.2

Incidence rates by quinquennium and sex Incidence rates by quinquennium and sex Sex ratio by quinquennium and sex Numbers by age and quinquennium, males Numbers by age and quinquennium, females Incidence by age and quinquennium, males Incidence by age and quinquennium, females Incidence rates by age, sex and decennium Incidence rates by age, sex and decennium Colon, incidence by birth cohort, males Colon, incidence by birth cohort, females Rectum, incidence by birth cohort, males Rectum, incidence by birth cohort, females Incidence by quinqueinium, sex and subsite Incidence by quinquennium, sex and subsite Distribution by decenium, sex and subsite Incidence by decennium, sex and subsite histology

Table 3.3

Adenocarcinoma and anaplastic carcinoma: distribution by site

Table 3.4 Proportions with no histology by quinquennium

Table 3.5 Annual survival by histological verification 66 Figure 3.5 
Figure 3.6

Annual survival by histology

68

Annual survival by histology 69

Table 3.7 Adenocarcinoma and anaplastic carcinoma: annual survival by differentiation $\quad 70$

Table 3.8

Adenocarcinoma and anaplastic carcinoma: percentage resected by differentiation 72

Table 3.9

Annual survival by differentiation

Annual survival by differentiation

74

Figure 3.9

Table 3.10

Distribution by treatment policy and differentiation

75

Figure 3.10

Dukes staging

Table 3.11

Distribution by Dukes stage and differentiation

76

77

Figure 3.11

Distribution by Dukes stage and differentiation

Table 3.12

5 year survival by Dukes stage and differentiation

Figure 3.12

5 year survival by Dukes stage and differentiation

Summary

83

Table 4.1 First symptom: proportions specified

85

\section{Type of first symptom}

Table 4.2.1

Colon: distribution by type

86

Colon: distribution by type 87

Table 4.2.2

Rectum: distribution by type

88

Figure 4.2.2

Rectum: distribution by type

Table 4.3

Distribution by site

89

Table 4.4.1

Median duration by type of symptom

90

Figure 4.4.1

Median duration by type of symptom

Table 4.4.2 Proportion curatively resected by type and duration

91

92

\section{Duration of symptoms}

Table 4.5 Distribution

94

Table 4.6.1 Colon: distribution by quinquennium 96

Figure 4.6.1 Colon: distribution by quinquennium 96

Table 4.6.2 Rectum: distribution by quinquennium 97

Figure 4.6.2 Rectum: distribution by quinquennium 97

Table 4.7 Distribution by age 98

$\begin{array}{lll}\text { Figure 4.7 } & \text { Distribution by age. } & 99\end{array}$ 
Table 4.8 Distribution by extent of disease and treatment

Figure 4.8

Distribution by extent of disease and treatment

Table 4.9 Annual survival

102

Figure 4.9

5 year survival

103

Table 4.10

Duration of symptom: curatively treated

Figure 4.10

5 year survival by node status

104

Table 4.11

5 year survival by node status and extent of disease

5 year survival rates by Dukes stage 106

Table 4.12

5 year survival by size of primary

108

Table 4.13.1 Node negative: 5 year survival by size of primary

Table 4.13.2 Node positive: 5 year survival by size of primary

Table 4.13.3 Nodal status not known: 5 year survival by size of primary

Table 4.14.1 5 year survival by differentiation and size of primary

Table 4.14.2 Curatively treated: 5 year survival by differentiation and size

Table 4.15 Interval to treatment

Summary

Table 5.1

Distribution by type of treatment

Figure 5.1

Distribution by type of treatment

Table 5.2.1

Colon: distribution by treatment and age

Table 5.2.2

Rectum: distribution by treatment and age

Figure 5.2

Distribution by treatment and age

Figure 5.3

Distribution by treatment and quinquennium

123

Table 5.3.1

Colon: Distribution by treatment and quinquennium

Table 5.3.2 Rectum: Distribution by treatment and quinquennium

Table 5.4 Annual rates, crude and age adjusted

5 year rates, crude and age adjusted by treatment 
Table 5.8

Figure 5.8

Table 5.9

Figure 5.9

Table 5.10

Table 5.11

Table 5.12

\section{Curatively treated}

5 year survival by treatment \& quinquennium 134

5 year survival by treatment \& quinquennium 135

5 year rates, crude and age adjusted by treatment and decade

Annual survival by treatment and decade 137

1 month mortality by treatment and decade 138

1 month mortality by decade, age and operation

5 year rates, crude and age adjusted by treatment and decade (excluding deaths within 1 month)

Summary

Table 6.1 Distribution and 5 year survival by extent of disease

Table 6.2

5 year rates, crude and age adjusted by stage

Curatively treated: distributions, 1 month mortality and survival

\section{Overall}

Table 6.3.1

Figure 6.3.1

Dukes $A B$ (node negative)

Dukes $A B$ (node negative)

Dukes $C$ (node positive)

148

Figure 6.3.2

Dukes C (node positive)

149

Table 6.3.3

Nodal status not known

150

Figure 6.3.3 Nodal status not known

\section{By sex}

Table 6.4.1

Dukes $A B$ (node negative)

Dukes $A B$ (node negative)

153

Table 6.4.2 Dukes $C$ (node positive)

154

Figure 6.4.2

Dukes C (node positive)

155

Nodal status not known

156

Table 6.4.3

Nodal status not known

Table 6.5.1

By age

Figure 6.5.1

Dukes $A B$ (node negative)

158

Dukes $A B$ (node negative)

Table 6.5.2

Dukes $C$ (node positive)

162

Dukes C (node positive)

163

Figure 6.5.2

Nodal status not known

164

Figure 6.5.3

Nodal status not known. 
By duration of symptoms

Table 6.6.1 Dukes $A B$ (node negative) 166

Figure 6.6.1 Dukes AB (node negative) 167

Table 6.6.2 Dukes C (node positive) 168

Figure 6.6.2 Dukes C (node positive) 169

Table 6.6.3 Nodal status not known 170

Figure 6.6.3 Nodal status not known 171

Table 6.7.1 Dukes AB (node negative) 172

Table 6.7.2 Dukes C (node positive) 173

Table 6.7.3 Nodal status not known 174

7 Palliative or no Treatment 175

\begin{tabular}{|c|c|c|c|}
\hline & & Summary & 175 \\
\hline & & Palliative resection and/or adjuvant therapy & \\
\hline Table & 7.1 & Type of treatment and one month mortality & 1 \\
\hline Table & 7.2 & Annual rates, crude and age adjusted & 1 \\
\hline Table & 7.3 & Survival by type of treatment & \\
\hline Table & 7.4 & Reasons for no curative treatment & \\
\hline Table & 7.5 & Survival by reasons & \\
\hline & & No definit & \\
\hline abl & 7.6 & Type of treatment and one month mortality & \\
\hline Table & 7. 7 & Annual rates, crude and age adjusted & \\
\hline Table & 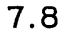 & Survival by type of treatment & \\
\hline Table & 7.9 & Reasons for no definitive treatment & \\
\hline Tab. & 7.10 & Survival by reasons & \\
\hline
\end{tabular}

8 Unusual tumours $\quad 185$

Summary 185

Table 8.1 All malignant tumours: numbers by histology 186

Table 8.2 All malignant tumours: distribution by histology

Malignant carcinoid tumours

Table 8.3 Numbers by site, quinquennium and sex 188

Table $8.4 \quad$ Numbers by site and age 188

Table 8.5 Incidence rates by site and age 189

Table 8.6 Annual rates, crude \& age adjusted by site 190

Table $8.7 \quad 5$ year rates, crude and age adjusted by site and sex 191

Table $8.8 \quad 5$ year rates, crude and age adjusted by site and treatment 


$\begin{array}{cll}\text { Table } 8.9 & \begin{array}{l}\text { Squamous cell carcinoma } \\ \text { Table } 8.10\end{array} & \begin{array}{l}\text { Numbers by site and sex } \\ \text { rates by quinquennium and sex }\end{array} \\ \text { Table } 8.11 & \begin{array}{l}\text { Rectum and anal canal: distribution by } \\ \text { sex and age }\end{array} \\ \text { Table } 8.12 & \begin{array}{c}\text { Rectum and anal canal: annual rates, } \\ \text { crude and age adjusted }\end{array} \\ \text { Table } 8.13 & \begin{array}{r}\text { Rectum and anal canal: } 5 \text { year rates, } \\ \text { age adjusted by type of treatment }\end{array}\end{array}$

\section{Prognostic factors}

Figure 9.1

Figure 9.2

Figure 9.3

Figure 9.4

Table 9.1

Figure 9.5

Figure 9.6

Figure 9.7

Table 9.2

Figure 9.8

Figure 9.9

Figure 9.10

Table 9.3

Figure 9.11

Figure 9.12

Figure 9.13

Table 9.4

Table 9.5

Table 9.6

Table 9.7

Table 9.8
Summary

197

198

199

Distribution by type of treatment

201

Proportion not treated by age

$\begin{array}{ll}5 \text { year survival rates by age } & 201 \\ 1 \text { month mortality by age and operation } & 203\end{array}$

Curatively resected: 5 year survival by age (excluding 1 month mortality) 203

Curatively resected: 5 year rates by nodal status, duration of symptoms and extent of disease

Distribution by treatment \& quinquennium

Curatively resected 1972-81: 5 year rates and 1 month mortality by operation

5 year rates by treatment, quinquennium and operation

Curatively resected: 5 year rates by nodal status and histology

Curatively resected, adenocarcinoma: 5 year rates by nodal status and duration of symptoms

Distribution of histological type by site 213

Curatively resected, adenocarcinoma, 1972-81: 5 year rates by size and differentiation

Curatively resected, 1977-81: annual rates by Dukes stage.

Curatively resected: annual rates by nodal status

Curatively resected: 5 year rates by nodal status and site

Survival analysis with covariates: I 219

Survival analysis with covariates: II 219

Survival analysis with covariates: III 221

Survival analysis with covariates: IV 223 
Appendix 1 Standardized Rates

A1.1 Standardized incidence rates

A1.2 Survival rates

A1.3 Age adjustment of survival rates

A1.4 Numerical illustrations

Appendix 2 Census and inter-censal populations 


\section{Foreword}

For the past generation the Birmingham Cancer Registry has been collecting statistics of cancer patients from the West Midlands, the largest region in the N.H.S. with a population of over $5 \mathrm{milli}$ ion. This collection has been meticulous and all cases have been analysed in detail; the scientific approach has produced valid data regarding the many aspects of malignant disease - diagnosis, clinical course, the results of treatment and the survival of the various subsets.

Over the years a number of $\mathrm{Cl}$ inical Cancer Monographs have been published and have come to occupy an important place in the literature of malignant disease. This volume is the latest in the series and deals with cancer of the large bowel - colon, rectum and anus. It represents the combined experience of all the centres in the region; in all 50,083 cases have been included and studied over the course of more than a quarter of a century, from 1957 to 1985.

Cancer of the large bowel is one of the major cancers, responsible for more than 20,000 deaths per annum in this country. This review shows that there has been a steady increase in incidence in recent years in all four groups - colon and rectum in males and females. The overall 5 - year survival rate is $27.2 \%$ and in only half the patients is curative resections possible; these figures portray the general poor prognosis. The series is unselected and comprehensive, providing a factual picture of the incidence and natural history of the condition in the community, rather than the selected results obtained at special centres.

The study is retrospective but should not be devalued on this count as the basic scientific research into this large scale clinical study establishes the foundation of the biological nature of the condition and its response to treatment. Reviews of this dimension are just as important and valid as those of small selected groups of patients enjoying a high curability rate.

The statistical methodology and validation procedures fully justify the conclusions reached and the authors are to be congratulated on the clear presentation of histology, epidemiology, clinical course, results of treatment - both curative and palliative - and the survival figures. The prognistic factors discussed in the last chapter will be of lasting interest to clinicians dealing with this type of cancer.

Oliver Goldsmith said "The volume of nature is the book of knowledge"; this is an outstanding example and it gives me great pleasure to commend it.

Professor P. Gilroy Bevan, CBE, Ch.M, FRCS. 


\title{
Acknowledgements
}

The authors acknowledge with gratitude the help of everyone who has contributed to the preparation of this Monograph and especially those listed below.

\section{THE CANCER RESEARCH CAMPAIGN}

The Cancer Research Campaign has generously provided the entire funds for the small Monograph Research Team who have been responsible for all the analytical work and for the preparation of tables, graphs and diagrams.

\section{REGIONAL CANCER REGISTRY}

The original data on which this series is based is entirely from the Birmingham and West Midlands Regional Cancer Registry.

We thank all those who - over many years - have given so generously of their time and expertise to ensure the completeness and accuracy of the data in the Registry. These include:

From the Registry:

All the staff both past and present.

From hospitals:

Consultant clinicians and pathologists

Administrators

Junior medical staf $f$

Laboratory technicians

Medical records staff and medical secretaries

Throughout the Region:

\author{
Coroners \\ General Practitioners \\ Staff of Family Practitioner Committees
}

Nationally:

The staffs of the Cancer Registration Sections of:

The Office of Population Censuses and Surveys.

The National Health Service Central Register.

From the University of Birmingham:

The staff of the Computer Centre. All the illustrations were produced using Tellagraf on the University's IBM Computer.

From the Monograph Team:

Mrs. Vanessa Chadderton for her artistic and accurate preparation of the figures and the final layout

Mrs. Judy Connor and Mrs. Margaret Williams for their painstaking preparation of the text and tables. 